IJMCE

10,2

Received 16 November 2020 Revised 12 December 2020 18 December 2020

Accepted 19 December 2020

\section{Redefining mentorship in an era of crisis: responding to COVID-19 through compassionate relationships}

\author{
Kara Lasater, Christy Smith, John Pijanowski and Kevin P. Brady \\ Educational Leadership, University of Arkansas, Fayetteville, Arkansas, USA
}

\begin{abstract}
Purpose - The purpose of this study is to investigate mentorship practices during the COVID-19 pandemic and to consider how mentorship could be improved to support students of educational leadership (EDLE) during crises.

Design/methodology/approach - Participants in this collective self-study were four faculty members (i.e. the authors) within an EDLE program in one public, research-intensive university in the southern USA. Data sources were memos, email correspondence, reflective dialogue, course evaluations and meeting notes. Analysis involved dialogic engagement among the research team to identify emergent themes.

Findings - Analysis revealed five themes that reflect our collective experiences as mentors during the pandemic. These themes were challenges created by dismantled systems; meeting students' needs for understanding, flexibility and meaningful learning experiences; evolving personal-professional boundaries; grappling with our own sense-making and well-beingness; and clarifying values and priorities.

Practical implications - The pandemic exemplifies the need for a deeper conceptualization of mentorship that stimulates more intimate, compassionate relationships between mentors and mentees. When mentorship is grounded in compassion, intimacy and mutual vulnerability, it demonstrates a genuine ethic of care and concern for others that is supportive of well-being and serves as a model for mentees entering the profession.

Originality/value - This paper extends disciplinary knowledge by focusing on the mentorship of EDLE students during crises and provides insights on how mentorship could be enacted to mutually support mentor-mentee well-being.
\end{abstract}

Keywords Mentoring, Compassion, COVID-19, Crisis, Educational leadership, Psychosocial development, Well-being

Paper type Research paper

Mentorship serves a critical role in graduate programs responsible for educational leadership (EDLE) preparation. It provides opportunities to gain professional knowledge, seek professional advice related to complex challenges and gain confidence in the execution of various job responsibilities (Briscoe, 2019). Yet, in 2020, the first year of the pandemic, COVID19 dramatically changed many aspects of mentorship. In a matter of weeks, faculty transitioned their students to fully online academic experiences. When K-12 schools closed, they wrestled with the complexities of providing students quality field-based experiences. Moreover, faculty, along with students, grappled with feelings of fear, uncertainty, anxiety and stress. Ultimately, these challenges, and countless more, required faculty to engage in intensive, deeply personal mentorship that often extended beyond the traditional scope and boundaries of the mentormentee relationship. But, whether faculty were personally or professionally prepared to engage in this type of intimate mentorship likely varied from individual to individual, leading to disparities in the level of support EDLE students received as they navigated complex decisions within their K-12 systems and graduate school contexts.

Funding: None

Declarations of interest: None 
Among our EDLE faculty at the University of Arkansas, we recognized pragmatic and conceptual differences in our approaches to mentorship because of the pandemic. Yet, when we turned to the literature for guidance, we noticed there was limited research to support us in implementing mentorship practices to support students through these unprecedented times. Much of the existing research focuses on mentorship in online environments. There is also an emerging body of scholarship focused on mentorship for well-being (e.g. see Kutsyuruba and Godden, 2019), but the scholarship specifically related to mentorship during crises (Mullen, 2020 ) is scant. Thus, the purpose of this study is to investigate how our mentorship practices were influenced by COVID-19 and, ultimately, to deeply consider how we might improve our mentorship practices to support EDLE students in times of crises.

\section{Literature review}

\section{Mentorship in graduate education}

While there are many different theories of mentorship, we view mentorship as "a developmental relationship that is sustained and valued for humanistic reasons" (Mullen, 2012, p. 7). More specifically, it is "a learning process wherein relationships are the structures through which individuals and groups engage in conversations and experiences that help promote ongoing growth and development" (Cherkowski and Walker, 2019, p. 346). Mentorship is more than the passing down of professional knowledge and skills. It is a mutual commitment to support the holistic development and well-being of mentee and mentor (Woloshyn et al., 2019). As such, we view the desired "end" of mentorship as "human flourishing" (Cherkowski and Walker, 2019, p. 354).

At the graduate level, mentorship serves three interrelated functions: educational, professional and psychosocial development (Kumar and Johnson, 2017). Educational development typically consists of support and guidance to assist mentees in reaching their educational and career goals. Activities consistent with educational mentorship include academic program planning, course selection, goal-setting and navigating institutional requirements and processes (Kumar and Johnson, 2017; Nora and Crisp, 2007). Professional development refers to support and guidance to enhance mentees' knowledge of the field and potential for career advancement (Kumar and Johnson, 2017; Mullen, 2012). It is particularly advantageous in pre-service preparation, as it provides mentees access to professional guidance prior to entering the field (Briscoe, 2019). Activities consistent with professional development mentorship include feedback on mentees' field-based performance and critical dialogue about job-specific challenges. Finally, psychosocial mentorship refers to the provision of support and guidance to facilitate mentee's intrapersonal growth and well-being (Kumar and Johnson, 2017). Activities consistent with psychosocial mentorship include listening, rolemodeling and counseling (Mullen, 2012; Nora and Crisp, 2007). While each developmental aspect of mentorship is essential and mutually connected to mentees' success and well-being, the field predominantly focuses on professional development (Mullen, 2012, 2020).

\section{E-mentoring}

Currently, many graduate programs, especially in EDLE, are offered online. Thus, research related to e-mentorship is rapidly expanding. E-mentoring refers to the use of visual, audio and text-based electronic communications to facilitate mentoring activities (Butler et al., 2013), and it involves the use of technologies that can facilitate synchronous (e.g. video conferencing, phone calls, etc.) and asynchronous (e.g. email, discussion boards, etc.) communication between mentor and mentee (Kumar and Johnson, 2017).

E-mentorship presents opportunities and challenges for the field. Challenges include the absence of non-verbal cues in communication and the increased time required to establish relationships (Butler et al., 2013; Kumar and Johnson, 2017). Advantages include access to mentorship across geographic distance and increased flexibility related to mentorship 
IJMCE 10,2

activities (Briscoe, 2019; Butler et al., 2013), which are vital for mentees who work full time (Kumar and Johnson, 2017). E-mentoring can provide students with transformational learning experiences by facilitating reflective dialogue between mentors and mentees and allowing mentees to learn from a diverse group of geographically dispersed mentors (Butler et al., 2013). E-mentoring could be particularly advantageous during crises. When mentees experience abrupt life changes, such as those spurred by COVID-19, e-mentoring provides an expedient way for mentors to offer support (Fletcher, 2012).

\section{Role of mentors}

When mentorship is viewed as a developmental relationship, mentors consider how they can support students beyond traditional supervisory and advisory activities. They seek to make a difference in the lives of their mentees, encourage and model professional risk-taking and constantly consider how they can learn from their mentees to improve their personal and professional selves (Mullen, 2012). They also candidly discuss and model for mentees the value of personal well-being (Woloshyn et al., 2019). This requires strong interpersonal skills, extensive professional knowledge and skills and an individual ideology that embraces democratic learning, shared leadership, collaboration and a genuine concern for others' wellbeing (Cho et al., 2011; Mullen, 2012).

Successful mentors are compassionate, insightful, honest, supportive and selfless (Cho et al., 2011), and they care about the holistic well-being and development of mentees (Cherkowski and Walker, 2019). Students appreciate and benefit from mentors who demonstrate a sincere interest in them, are confident yet realistic about their professional abilities and provide space and support for students to develop into autonomous learners (Al Makhamreh and Stockley, 2019). Additionally, effective mentors in online environments are comfortable meeting informally with mentees, able to collaborate with others and competent in the use of technology (Fletcher, 2012; Mullen, 2020).

Conversely, ineffective mentors can have a deleterious effect on students' development and well-being. This is particularly the case when mentors are overly authoritative, negative, absent physically/virtually or unavailable psychologically (Al Makhamreh and Stockley, 2019). When mentors demonstrate these attitudes and behaviors, students have expressed feeling helpless, hopeless, overlooked and disrespected, which can influence their academic progress and overall mental health and well-being (Al Makhamreh and Stockley, 2019).

Faculty in EDLE programs are likely well suited to provide mentees with professional and educational mentorship; however, they are less likely to have expertise in psychosocial aspects of mentorship (Condra et al., 2015). This is in part because emphasis on psychosocial mentorship has evolved gradually and more recently (Mullen, 2012). But, it is also because the knowledge and skills needed for psychosocial mentorship are highly specialized. Psychosocial mentorship requires active listening skills, appropriate responding skills and a degree of distress tolerance (Woloshyn et al., 2019). It also requires a willingness from mentors to be vulnerable and sincere with their mentees (Al Makhamreh and Stockley, 2019). Unfortunately, this aspect of mentorship is often considered outside the scope of traditional mentorship activities (Mullen, 2012), and many faculty members never receive the training or support necessary to feel efficacious mentoring in ways that support students' mental health and well-being (Condra et al., 2015). Nevertheless, it is mentorship in this area that may prove most advantageous to students as they navigate the psychological, socio-emotional and professional challenges associated with crises.

\section{Conceptual framework}

\section{Leadership during crises}

Crises are harmful events that threaten people, groups, organizations, societies or cultures and require urgent attention and mitigation by leaders (Boin et al., 2017). They extend beyond 
complex problems or challenges by disrupting the core structures, routines, norms and values upon which people and organizations rely, and they create a sense of disorder, shock and vulnerability at micro and macro levels (Boin et al., 2017; Pepper et al., 2010). While there are various types of crises (economic, natural disaster, etc.), they share three features: threat, urgency and uncertainty (Boin et al., 2017).

Leaders play a critical role in planning for and urgently responding to crises within their organizations. They are expected to prepare for crises by building trust with stakeholders, fostering organizational resiliency and monitoring the environment for potential threats (Pepper et al., 2010; Spillane and Lee, 2014). In response to crises, school leaders are expected to identify the immediate priorities of the organization; allocate time, resources and efforts according to identified priorities; and communicate effectively with diverse stakeholders (Pepper et al., 2010). However, the cumulative ambiguity, urgency and gravity of crises create a challenging decision-making context for leaders. As Boin et al. (2017) described, crises:
Redefining mentorship

...create a distinctive and sometimes seemingly impossible task environment for leaders: they require urgent decisions while essential information about causes and consequences remains unavailable; they require effective communications to a variety of audiences with widely differing needs, views, and frames of references (p. 12).

Despite these challenges, "leaders are expected to chart pathways out of the crisis" (Boin et al., 2017, p. 3), and this expectation places considerable pressure on school leaders. K-12 leaders often respond to this pressure by adopting a normative orientation of service to others (StoneJohnson and Weiner, 2020). Consequently, they often feel a sense of ultimate responsibility to protect people in their care, which can lead to exhaustion, solitude and personal neglect, ultimately jeopardizing leaders' well-being (Pepper et al., 2010; Ray et al., 2020; Spillane and Lee, 2014).

\section{Mentorship for well-being}

Systems of support play a critical role in sustaining and rejuvenating school leaders during crises (Pepper et al., 2010). Mentorship is one such support system that could assist EDLE students as they navigate crisis challenges. Though the literature specifically related to mentorship during crises is limited, the literature on mentorship for well-being offers a valuable lens that could assist mentors and mentees. We conceptualize mentorship for wellbeing as caring, compassionate and attentive relationships between mentors and mentees that reciprocally foster personal and professional development by nurturing and prioritizing educators' holistic well-being and fulfillment (Kutsyuruba and Godden, 2019; Lucey and White, 2017; Nora and Crisp, 2007). From this perspective, mentorship recognizes the fullness of human identity; as such, it involves a deliberate attendance to the development of mentees' mind, body, spirit and soul (Cherkowski and Walker, 2019). Mentorship for well-being also involves an awareness of and responsiveness to sociopolitical issues (e.g. racism, classism, etc.) that impact students (Woloshyn et al., 2019). This is essential to consider in the context of COVID-19, as existing social inequities were illuminated and exacerbated throughout the pandemic (Fortuna et al., 2020).

The ability of mentorship to enhance well-being is substantially influenced by the quality of the mentor-mentee relationship (Lucey and White, 2017; Woloshyn et al., 2019). Mentors can develop caring, compassionate relationships with mentees by approaching their work from a strengths-based perspective, learning about mentees' lives in and outside the school context, attending to mentees' well-being, recognizing the extenuating circumstances that impact students and establishing a safe environment for critical dialogue (Cherkowski and Walker, 2019; Woloshyn et al., 2019). When the mentorship relationship is grounded in trust and authentic care, it creates opportunities for reciprocal support and growth for mentees and mentors (Lucey and White, 2017; Varney, 2009). 
IJMCE 10,2

162

We contend that mentorship for well-being is particularly important for EDLE students during crises, as these students are typically employed within K-12 systems and they subsequently face tremendous professional responsibilities amid crises. Crises bring on intense feelings of uncertainty, fear, stress, vulnerability and anxiety (Boin et al., 2017; Pepper et al., 2010); fear and isolation can have a damaging effect on an individual's professional performance and sense of well-being (Briscoe, 2019). Yet, mentors can serve as "an emotional safety net" by offering their mentees words of encouragement and ongoing support (Nora and Crisp, 2007, p. 349). When mentees are recognized as "growing, striving, and sometimes struggling" individuals (Varney, 2009, p. 129), compassionate mentorship can provide a relational anchor of mutual support and encouragement and serve as a powerful antidote to burnout amidst challenging professional circumstances (Trzeciak and Mazzarelli, 2019).

There is emerging research that describes how mentorship for well-being can be translated online. This is significant given that many EDLE programs are fully online, and COVID-19 necessitated that nearly all programs across the USA cease face-to-face mentorship activities. Virtual mentoring can occur synchronously and asynchronously, and these various modes of communication provide increased flexibility and broader access for communication between mentors and mentee (Kumar and Johnson, 2017). Perhaps even more crucial, the process of virtual mentoring can build confidence, diminish fears associated with professional uncertainties and decrease mentees' feelings of isolation (Briscoe, 2019). Ultimately, when a safe, supportive environment for self-reflection and critical dialogue exists, mentorship can empower mentees as they contemplate future actions, particularly amid complex, ambiguous challenges (Lucey and White, 2017).

The literature on crisis and mentorship for well-being clarifies how mentorship could support students; however, providing this type of mentorship necessitates that mentors have both the capacity and willingness to cultivate intimate relationships with mentees, as well as the knowledge and skills necessary to help them navigate crisis and trauma. Currently, research on mentors' ability and willingness to engage in mentorship for well-being is limited, but this line of inquiry is important, particularly for faculty who support current and future school leaders. During crises, future and current school leaders are not only tasked with overseeing the well-being of others, but they are responsible for making swift decisions to highly complex problems that can impact the well-being of their students, staff, families and communities in varied ways.

\section{Methods}

Research context

This collective self-study was conducted within the University of Arkansas's EDLE program, which is staffed by four full-time faculty members (i.e. the authors). As full-time faculty, we are responsible for the formal mentorship of all students in our three degree programs (master's, specialist, doctorate). While each faculty member has distinct formal mentorship responsibilities, we predominantly serve as a "constellation" of informal mentors by sharing responsibility for the support, guidance and development of all students in our programs (Butler et al., 2013, p. 241).

Coursework within our programs is fully online; however, we utilize synchronous class sessions, combined with asynchronous communication (discussion boards, VoiceThread, etc.), to facilitate critical dialogue among students and faculty. Additionally, our doctoral program follows a cohort model and requires students to participate in three on-campus seminars. The cohort model facilitates ongoing communication and socialization between students and faculty, and the seminars provide a valuable opportunity for students to connect face-to-face with faculty and other cohort members. Unfortunately, COVID-19 required us to move all oncampus events to virtual environments. 
As a faculty unit, we have worked together less than two years, but individually, our relationships span multiple decades. Kevin and John started their academic careers together more than 20 years ago, and John has mentored Kara for over a decade, first as a student and currently as a tenure-track professor. When Christy joined the team in 2019, she brought with her extensive experience as a K-12 leader and enthusiasm for the University of Arkansas and Arkansas schools. Unquestionably, we respect each other's professional capabilities, but, more importantly, we value one another's benevolence, humility, support, trustworthiness and care. These relationships manifest in our co-construction of curriculum, co-mentorship around teaching and collaborative research endeavors. Through our trusting relationships, and history of working in concert, we easily fell into dialogue about our experiences with students during the pandemic.

When COVID-19 first emerged, conversations among EDLE faculty occurred informally but routinely. Originally, these conversations centered on the imminent changes that would occur in the USA as a result of the virus. We discussed changes to conference scheduling, potential campus closure and the general safety and well-being of others. As those imminent changes became reality, our conversations shifted. We began to discuss the impact of K-12 school closures on our students, as most were employed full time as teachers and leaders. We discussed the challenges students experienced, as they juggled coursework, significant but changing professional responsibilities and the constant presence of their own children. We also discussed our own personal struggles as faculty and the varied ways in which we were impacted by COVID-19, some more deeply than others. The anxiety evoked by the pandemic was further complicated by multiple sociopolitical issues occurring in the USA throughout 2020, including a refocusing on racial inequities and a divisive presidential election. Pandemic-related reports of the disproportionate impact of the pandemic on communities of color added to an already volatile atmosphere (Fortuna et al., 2020). Collectively, the events of 2020 created a complex environment of unrest, dissention, fear and uncertainty for K-12 leaders and university faculty to navigate.

\section{Research design}

These complex events led us to consider the role of mentorship during crises and to engage in a collective self-study of our mentorship practices. Self-study refers to the systematic, reflective investigation of one's professional practice (Frick and Riley, 2010). It is used by educators to improve the preparation of pre-service teachers and leaders and, subsequently, the broader educational field (Bullough and Pinnegar, 2001; Frick and Riley, 2010). Self-study is initiated and focused on self; its purpose is to improve practice; it involves ongoing, collaborative dialogue to challenge assumptions and interpretations; it involves conventional and unconventional qualitative approaches to data collection and analysis; and its process and outcomes are publicly and explicitly shared within the field (LaBoskey, 2004).

Collective self-study extends the inquiry beyond individual practice to include an explicit focus on collective improvement (Samaras et al., 2016). It is particularly valuable when the goal of analysis is to improve organizational practice and facilitate change in professional culture (Davey and Ham, 2009). In our study, we were interested in improving our individual mentorship, but we were further concerned with how our collective, programmatic approaches to mentorship could assist students during times of extreme stress and uncertainty. As such, we utilized collective self-study to examine our mentorship throughout the pandemic and to deeply consider how we, as a program and field, might collectively improve our mentorship practices to support EDLE students during crises. More specifically, we utilized a "coformative" approach to self-study in which we each conducted our own self-studies as part of a collection, then collaboratively reflected on and critically considered our processes, emergent interpretations and evolving thinking (Davey and Ham, 2009, p. 188). The three research questions guiding our collective self-study were: 
IJMCE

10,2
(1) How did we change as mentors as a result of COVID-19?

(2) What can we learn from our mentorship experiences during COVID-19 that can inform the development of improved mentorship practices in times of crises?

(3) How can faculty support students' well-being and holistic development during crises?

Data sources

Consistent with collective self-study, we utilized autobiographic and correspondence data (memos, emails, reflective dialogue, course evaluations and collaborative meeting notes) to answer our research questions (Bullough and Pinnegar, 2001; Samaras et al., 2016). Keven relied predominately on email correspondence, reflective dialogue and course evaluations in his analysis, whereas Christy, Kara and John utilized these data sources while also engaging in ongoing structured memo writing. These structured memos explored faculty's mentorship practices related to the three functions of mentorship (educational, professional and psychosocial development) at various points in time (prior to COVID-19, during the spring semester of 2020 as the pandemic spread across the USA, and in preparation for fall 2020 as schools and universities reopened amidst the pandemic).

Additionally, email correspondence data represented "a kind of intellectual autobiography of the moment" (Bullough and Pinnegar, 2001, p. 16) and allowed us to gain an authentic, realtime view of our mentorship. Specifically, we mined our inboxes from January 1 to October 1 , 2020, and extracted email correspondences related to student mentorship. We also analyzed data from our spring and summer course evaluations.

Finally, we engaged in reflective dialogue to collectively examine our mentorship practices (Samaras et al., 2016). This reflective dialogue began in spring 2020 and continued while working on and completing this paper in fall of the same year. Reflective dialogue often occurred spontaneously among our team; however, it also occurred more formally in our EDLE team meetings. The purpose of the reflective dialogue was to discuss our mentorship experiences throughout COVID-19 and to consider, challenge and refine our thinking about faculty mentorship. Kara captured data from reflective dialogue through meeting notes and journaling.

\section{Data analysis}

We engaged in a "three-pronged" approach to data analysis: data organization and management, immersive engagement with the data and writing and representation (Ravitch and Carl, 2016, p. 239). Data were organized using a shared folder, and we uploaded our individual data sources (emails, memos, etc.) to the folder. We then immersed ourselves in the data and engaged in dialogue to generate, scrutinize and vet our emergent themes (Ravitch and Carl, 2016).

Dialogic engagement served as a critical component of our analytic process (Ravitch and Carl, 2016; Samaras et al., 2016). This occurred during our team meetings and involved collaborative, critical discussions of our mentorship experiences during COVID-19. We also discussed our perceptions of students' experiences and evolving thoughts about mentorship. In a sense, these meetings served as a co-directed, unstructured focus group in that we shared stories, asked questions and commented on each other's perspectives. After exploring our unique and shared experiences, we arrived at identified themes (Ravitch and Carl, 2016). Through this process, we challenged each other as "critical friends" to deeply reflect on our individual and collective practice and to consider alternative explanations of our thinking (Samaras et al., 2016; Tidwell and Staples, 2017). This collaborative process is imperative in establishing the trustworthiness of self-studies (Vanassche and Kelchtermans, 2015), and, in collective self-studies, it serves to ensure that research teams meet individual and collective 
improvement goals while moving toward a deeper awareness of practice (Tidwell and Staples, 2017).

\section{Limitations}

There are two primary limitations to this study. First, it relied heavily on researcher-generated data produced by four faculty members. Thus, the findings are not generalizable and only minimally reflect the student experience (through course evaluations). Future research should explore how students experience mentorship during crises and incorporate additional data sources. Second, as faculty, we experienced firsthand the challenges associated with mentoring EDLE students during the pandemic. Our study emerged organically as a mechanism to better understand and address the real-time challenges we experienced. However, our intentional focus on mentorship likely influenced our retrospective accounts of our mentorship practices (captured in the structured memos) and our enactment of mentorship moving forward. In other words, our data were likely influenced by our participation in this self-study. While we recognize this limitation, we also acknowledge self-study as a form of personal and professional development and appreciate how our professional practice progressed through this critical, reflective inquiry (Bullough and Pinnegar, 2001).

\section{Findings and discussion}

Our joint analysis revealed five themes that reflect our collective experiences as mentors during the 2020 crisis events: challenges created by dismantled systems; meeting students' needs for understanding, flexibility and meaningful learning experiences; evolving personalprofessional boundaries; grappling with our own sense-making and well-beingness; and clarifying values and priorities. Though these themes represent our collective experiences, we did not experience the phenomena identically. We next discuss the themes and discrepancies in faculty experience are discussed.

\section{Challenges created by dismantled systems}

The pandemic disrupted many systems and structures foundational to the university's core functions of teaching and learning (Pepper et al., 2010). These dismantled systems created three challenges that significantly impacted our mentorship. First, the university's Institutional Review Board (IRB) halted all face-to-face data collection in spring 2020. This required doctoral students to unexpectedly change the designs of their dissertation studies, and we collectively felt a sense of responsibility to assist students through these changes. As Kara described:

The student I was chairing was also stressed because of the potential changes to data collection ... . my responsibility was to support her and to alleviate any additional stress. . I tried to be solutionsfocused and calming - reassuring her that we might need to think innovatively about how to proceed but that we would, if needed, develop a plan that would be meaningful and feasible.

Though we strived to help students navigate changes in university processes and policies, providing this assistance was challenging given the many "unknown unknowns" associated with COVID-19 (Boin et al., 2017, p. 8).

Second, office closures across campus led to significant delays in basic university processes (e.g. admitting and enrolling students), making it difficult for both students and faculty to fulfill their respective responsibilities. Kevin felt the weight of these procedural delays. As the EDLE program coordinator, he was responsible for admitting students into our programs, enrolling them into appropriate coursework and ensuring all courses obtained minimum enrollments established by the university. Unfortunately, Kevin could not complete these tasks without the 
IJMCE

10,2

approval of other campus offices, and procedures within these offices were disrupted with the transition to remote services. In response, many students messaged Kevin incessantly for assistance and updates, increasing the stress, pressure and helplessness he was already experiencing. John also believed these delays were problematic for program sustainability. Recognizing that COVID-19 could threaten the viability of university programs, he believed that faculty could proactively address this concern by maintaining or increasing student enrollment in our programs. Procedural delays in enrollment processes hindered our proactive efforts.

Finally, field-based course requirements (internships) created additional challenges for students and faculty. This challenge was particularly salient for Christy, the faculty supervisor of student internships. When K-12 schools closed, Christy quickly worked to establish meaningful, non-traditional field-based experiences and to fill the void left by the limited access students had to their field-based mentors. As she described:

When schools closed in March 2020, the plans developed in January for interns to complete on-site activities and accumulate internship hours evaporated. Knowing that mentors' time was now consumed with creating systems to serve students remotely and fill the service gaps created by the closure of schools, the frequency of my communication with interns increased... As interns described how their mentors' responsibilities were evolving, I suggested internship activities directed toward those changes.

The dismantling of systems was an evolving challenge for faculty, as new "phases" of the pandemic brought more procedural breakdowns. The key for us as mentors was learning to provide continuous support to students when the systems designed to support them were in disarray.

\section{Meeting students' needs for understanding, flexibility and meaningful learning experiences}

Throughout the pandemic, we were acutely aware of hardships faced that were exacerbated by students' work as K-12 educators. Consequently, a persistent challenge of ours was meeting students' need for understanding and flexibility in their coursework while also meeting their need for a meaningful learning experience. John's reflection illustrates this challenge:

I quickly realized the amount of collective grief, concern, and frustration they [students] were experiencing and how that was bleeding over into their academic experience.... for many of them the work we were asking them to do seemed impossible in light of all they were dealing with at work and at home. They needed more direct guidance about how to balance those things as well as more support in adapting to new obstacles and reassurance that we would support them. ... they still came to us with academic and career goals in mind and the work has to be at the center of what we do together.

Collectively, we developed a heightened awareness of students' psychosocial needs and our role as mentors in attending to those needs; however, we also recognized our responsibility for ensuring that students received a meaningful educational experience. The key for us as mentors was learning to balance this with students' needs for flexibility and understanding while simultaneously recognizing when the pendulum necessarily needed to swing in a certain direction, which varied from student to student and moment to moment.

At the onset of COVID-19, the pendulum seemingly tilted toward understanding and flexibility. As an email message from Kevin to his students illustrates:

I so appreciate you being completely honest with me, especially as it relates to the impact of selfisolation and lack of motivation as a result of this terrible pandemic. I, too, have struggled (continue to) with focus and trying to effectively multi-task... . Trust me, you are not alone. Several students have already emailed me and are struggling to continue working in their classes. I realize this and will make every effort for the remainder of the course to focus on learning and not grades. 
As the crises persisted throughout the summer and fall, the pendulum swung back toward a more intentional focus on student learning. Though we remained responsive to students' needs, we also leveraged 2020 events as a rich context for deeply exploring course content.

\section{Evolving personal-professional boundaries}

COVID-19 quickly eroded the boundaries between our personal and professional selves. As work functions moved to our homes, we no longer had the option of trying to keep our personal and professional lives separate, and the loss of these boundaries increased our willingness to be open, honest, vulnerable and intimate with mentees. We demonstrated this willingness in our explicit actions of supporting students beyond educational and professional development. As Christy described:

Class was a safe space for students to be transparent. None of us had escaped the fears that accompanied the pandemic, yet we still had families to care for and jobs to do. As the professional/ personal boundaries blurred organically, we shared our individual experiences, expressed compassion, and confronted our collective vulnerability. The cathartic effect provided moments of respite from which we drew temporary strength.

Additionally, Christy and Kara recognized that they were more willing and intentional about telling students, "I'm thinking about you" - a simple message of caring they were not accustomed to sending prior to COVID-19.

We also demonstrated our willingness to be open, honest and vulnerable with mentees by sharing our personal experiences of the pandemic and acknowledging our individual limitations. This intimate self-disclosure is evident in John's message to students:

I am writing to let you know that I will be cancelling our scheduled Collaborate Ultra session tonight. My father has been hospitalized with COVID-19 symptoms and is on a ventilator. We learned moments ago he is in a coma and my brothers and I will need to make some decisions this evening. . . I had been spending a lot of time thinking about how to approach this class anyway - is it better to press on because we can and so it becomes a distraction from the other hardships around us, or is it foolish to try to press on and ignore that our lives are very much different right now. . . I want to do right by your effort in this class and give you the experience you deserve. I will give you my best shot. But tonight my family needs me.

In the class session following his dad's passing, John asked students what questions they had, presumably about course content. Someone immediately responded, "I only have one question. How are you?' John shared that he was sad but present, and this heartfelt exchange seemingly freed students to share their own grief throughout the semester. Prior to COVID-19, we did not routinely self-disclose information about our personal lives, but this type of exchange occurred with increasing frequency throughout the pandemic. In response, students often shared heartfelt messages of comfort and support, exemplifying how the mutual sharing of information and reciprocal provision of support can facilitate comfort, healing and growth for mentors and mentees (Lucey and White, 2017; Varney, 2009).

Though we all experienced the loss of personal-professional boundaries and an increased willingness to be open, honest, vulnerable and intimate with our mentees, we varied in our initial "readiness" to embrace this type of mentor-mentee relationship. For Kevin, this level of intimacy and vulnerability with students was initially disconcerting, as he described:

I found myself toward the end of the semester checking on the emotional well-being of students and sharing with students my own trials and tribulations with dealing with COVID-19. Something I rarely do. I think the students appreciated my vulnerability but it was a foreign and uncomfortable place for me as the professor.

Conversely, Kara found compartmentalizing her personal and professional life exhausting and disingenuous. She considered this new degree of openness, intimacy and vulnerability 
IJMCE

10,2

168 liberating, believing it gave her license to be her whole, authentic self with students. Eventually, we all came to appreciate the connections we developed with students, but it was a process that evolved at different rates for each of us.

\section{Grappling with our own sense-making and well-beingness}

While we worked to support mentees, we were also grappling with our own feelings of anxiousness, stress, fear and sadness. These feelings led us to engage in ongoing reflection, sense-making and meaning-making that was emotionally, physically, intellectually and spiritually daunting. In the following passage, Kara describes how her constant efforts to make sense of the pandemic jeopardized her well-being:

I followed the pandemic coverage closely when it first began, but eventually, I had to stop. The mixed messages, disparaging and hateful reporting of the virus and other news, and the politicized nature of the virus coverage became really unhealthy to me. . .. I think these feelings ultimately shifted how I felt about the pandemic and my beliefs about how we should all be acting in response to it.

What Kara perceived as ambiguous and contradictory messaging about the pandemic led her to feel a sense of "cognitive conflict" (Boin et al., 2017, p. 80). She eventually made sense of this conflict by "doubling down" on her existing beliefs about the importance of connections, love, intimacy and physical contact with others. Through the sense-making and meaning-making process, Kara felt recommitted to her personal values and beliefs, but she remained exhausted by continuously wrestling with how best to exercise those beliefs and values during the pandemic.

The exhaustion we felt was further exacerbated by our heightened attention and responsiveness to students' well-being. Christy described how she felt an increased sense of "ultimate responsibility" for student success. To alleviate additional stress and feelings of panic, she worked tirelessly to support students, sometimes at the detriment of her own wellbeing. As Christy reflected:

COVID-19 led to the realization that the mentor-mentee relationship was a lifeline for students ... They were overwhelmed as they attempted to strike the balance between their responsibility as educators, parents, and graduate students. I felt an ethical imperative to create respite. I knew that the leadership I exhibited during this crisis would contribute to the model they use when they become building and district leaders. I willingly took upon myself a portion of the weight I would normally expect my students to bear. Many were at the breaking point and I felt it was my duty to temporarily stand in the breach for them. I knew that I would bend from the additional load but was confident I could bear it temporarily.

As this passage illustrates, recognizing and empathetically responding to the complexities of mentees' lived experiences are critical to mentorship for well-being, but it is emotionally laborious work for mentors (Woloshyn et al., 2019).

For Kevin, the laborious nature of this work during the pandemic took a toll on his wellbeing. Kevin described feeling frustrated by the increased volume of students' communication and what appeared to be a lack of sensitivity that the pandemic had placed increased professional and personal demands on faculty too. This stress was magnified by the closure of university offices and the slowed efficiency of systems that made it nearly impossible for him to properly fulfill his job responsibilities. Over time, these stressors led Kevin to experience burnout and question the effectiveness of university systems during COVID-19. Unfortunately, faculty well-being is not often prioritized within higher education, and this can further contribute to disengagement, depersonalization and burnout (Sabagh et al., 2018), all of which adversely impact the mentor-mentee relationship (Al Makhamreh and Stockley, 2019; Woloshyn et al., 2019). 


\section{Clarifying values and priorities}

The 2020 crisis events prompted continuous sense-making and meaning-making for us (Boin et al., 2017), and it is through this process of "cognitive rebuilding" that we clarified our values and priorities (Tedeschi and Calhoun, 2004, p. 5). What we came to remember was the value of people in our lives, and we reoriented our actions so that people were the center of our work not publications, reports, lectures or assignments. Accordingly, we became much more intentional about demonstrating compassion toward our students. As Kanov et al. (2004) described, "compassion provides comfort in a time of distress and disorientation and serves as a reminder to professionals of the human dimension of practices that can easily become exclusively system, function, or technique driven" (p. 812). Compassion goes beyond noticing and feeling someone's suffering. It involves deliberate efforts to alleviate it (Frost et al., 2006; Kanov et al., 2004). As faculty, we were particularly sensitive to challenges experienced by K-12 educators throughout the pandemic, and we intentionally strived to alleviate the suffering they experienced. As Christy described:

Our collective humanity is magnified when we are quite literally fighting for our lives... This led to a conscious decision to show flexibility and compassion to students, even if it increased my workload. Some had expressed the fear that they could not continue their studies, so my mantra became "we can do this; I will help you."

The limited data we collected regarding students' experiences suggested that students recognized and appreciated the compassion faculty demonstrated. As a student commented on Kevin's course evaluation, "I attended this class during the Corona Pandemic and Dr. Brady was kind, encouraging and showed us Grace throughout the course. He often inquired about our physical and emotional well-being during this unprecedented time." In hindsight, demonstrating compassion was probably one of the most influential ways we could serve, support and ease burdens. Compassion has the power to assist in physiological healing, ease feelings of pain, decrease emotional and psychological distress and improve overall quality of life and well-being (Trzeciak and Mazzarelli, 2019).

Our intentional focus on people and the demonstration of compassion also led us to seek deeper, more intimate connections with students. Eventually, these connections allowed us to witness their lives in more intimate, authentic ways. As John described:

Early on I noticed a lot of stress in their eyes and voices - many would come out of small group work and I could see they had just been crying or were on the verge of crying. I created as much space as I could for them to process what was happening in their work lives and cultivate a supportive atmosphere for that.

Though previously foreign to our courses, these intimate moments of crying were something we all witnessed and shared with students throughout 2020. According to Trzeciak and Mazzarelli (2019), "walking with people through the worst, most intimate moments of their lives is a sacred thing" (p. 10), and it is through these sacred moments shared with students that we found strength and solidarity. Even more, we began to recognize compassionate, intimate relationships with our students as not merely supplemental to our work, but fundamental to it (Frost et al., 2006).

\section{Conclusion}

Through the chaos and wreckage, crises create opportunities to learn, adapt, grow and transform (Boin et al., 2017; Tedeschi and Calhoun, 2004). In a matter of weeks, COVID-19 dismantled carefully constructed and historically entrenched boundaries between our personal and professional selves. Suddenly, the lines among home, work and school blurred, and perhaps for the first time ever, students and faculty routinely saw into each other's lives
Redefining mentorship 
IJMCE

10,2

in deeply personal ways. At times, the collapse of personal-professional boundaries created immense stress for us, but the authenticity with which we witnessed and took part in each other's lives also created beautiful opportunities to connect in more genuine, humane ways that ultimately allowed us to reconsider how mentorship is conceptualized and enacted in EDLE preparation programs.

Currently, the professional and educational development of students takes precedence in mentorship processes; however, emotional preparation for managing the demands of the profession is as fundamental as professional and educational knowledge (Briscoe, 2019). Thus, it is important to move psychosocial development to the forefront of mentorship processes. Mentees' psychosocial functioning and well-being underscore their ability to successfully engage in academic studies and fulfill professional demands. Furthermore, nurturing and attending to mentee's psychosocial development demonstrate a genuine ethic of care and concern that can foster individual well-being while serving as a model for mentees entering the profession.

The events of 2020 provide a rare opportunity to shift professional norms to reflect a better us and profession. We have the opportunity now to call into question what it is we value most and who it is we want to be moving forward (Boin et al., 2017). What we learned from our experiences is that compassionate mentorship matters, particularly during crises. As a "healing force," compassion can "help to make a heavy burden of suffering more bearable" (Frost et al., 2006, p. 843) not just for mentees, but for mentors too. Compassion in the mentorship relationship necessitates intimate knowledge about who people are, what they value and what they experience (Dewar and Cook, 2014). This is knowledge we obtained once the personal and professional boundaries between students and mentors collapsed, which need not be a momentary adaptation to a crisis. When mentorship is grounded in compassion, intimacy, vulnerability and authentic commitment to support the holistic well-being of others, it has the power to uplift, rejuvenate and heal - even in the most challenging of circumstances.

\section{References}

Al Makhamreh, M. and Stockley, D. (2019), "Mentorship and well-being: examining doctoral students' lived experiences in doctoral supervision context", International Journal of Mentoring and Coaching in Education, Vol. 9 No. 1, pp. 1-20, doi: 10.1108/IJMCE-02-2019-0013.

Boin, A., Hart, P., Stern, E. and Sundelius, B. (2017), The Politics of Crisis Management: Public Leadership under Pressure, 2nd ed., Cambridge University Press, Cambridge.

Briscoe, P. (2019), "Virtual mentor partnerships between practising and preservice teachers: helping to enhance professional growth and well-being", International Journal of Mentoring and Coaching in Education, Vol. 8 No. 4, pp. 235-254, doi: 10.1108/IJMCE-02-2019-0023.

Bullough, R.V. Jr and Pinnegar, S. (2001), "Guidelines for quality in autobiographical forms of self-study research”, Educational Researcher, Vol. 30 No. 3, pp. 13-21.

Butler, A.J., Whiteman, R.S. and Crow, G.M. (2013), "Technology's role in fostering transformational educator mentoring", International Journal of Mentoring and Coaching in Education, Vol. 2 No. 3, pp. 233-248, doi: 10.1108/IJMCE-06-2013-0037.

Cherkowski, S. and Walker, K. (2019), "Mentorship for flourishing in schools: an explicit shift toward appreciative action", International Journal of Mentoring and Coaching in Education, Vol. 8 No. 4, pp. 345-360, doi: 10.1108/IJMCE-02-2019-0018.

Cho, C.S., Ramanan, R.A. and Feldman, M.D. (2011), "Defining the ideal qualities of mentorship: a qualitative analysis of the characteristics of outstanding mentors", The American Journal of Medicine, Vol. 124, pp. 453-458, doi: 10.1016/j.amjmed.2010.12.007.

Condra, M., Dineen, M., Gauthier, S., Gills, H., Jack-Davies, A. and Condra, E. (2015), “Academic accommodations for postsecondary students with mental health disabilities in Ontario, Canada: 
a review of the literature and reflections on emerging issues", Journal of Postsecondary Education and Disability, Vol. 28 No. 3, pp. 277-291.

Davey, R. and Ham, V. (2009), "Collective wisdom: team-based approaches to self-study in teacher education", in Lassonde, C.A., Galman, S. and Kosnik, C. (Eds), Self-Study Study Research Methodologies for Teacher Educators, Sense Publishers, Rotterdam, pp. 187-203.

Dewar, B. and Cook, F. (2014), "Developing compassion through a relationship centered appreciative leadership programme", Nurse Education Today, Vol. 34, pp. 1258-1264, doi: 10.1016/j.nedt.2013. 12.012.

Fletcher, S.J. (2012), "Fostering the use of web-based technology in mentoring and coaching", in Fletcher, S.J. and Mullen, C.A. (Eds), The SAGE Handbook of Mentoring and Coaching in Education, Sage, London, pp. 74-88, doi: 10.4135/9781446247549.n6.

Fortuna, L.R., Tolou-Shams, M., Robles-Ramamurthy, B. and Porche, M.V. (2020), "Inequity and the disproportionate impact of COVID-19 on communities of color in the United States: the need for a trauma-informed social justice response", Psychological Trauma: Theory, Research, Practice, and Policy, Vol. 12 No. 5, pp. 443-445, doi: 10.1037/tra0000889.

Frick, W.C. and Riley, A.T. (2010), "A self-study on preparing future school leaders", Journal of Research on Leadership Education, Vol. 5 No. 9, pp. 310-334.

Frost, P.J., Dutton, J.E., Maitlis, S., Lilius, J.M., Kanov, J.M. and Worline, M.C. (2006), "Seeing organizations differently: three lenses on compassion”, Clegg, S.R., Hardy, C., Lawrence, T.B. and Nord, W.R. (Eds), Handbook of Organizational Studies, 2nd ed., Sage, London, pp. 843-866.

Kanov, J.M., Maitlis, S., Worline, M., Dutton, J.E., Frost, P.J. and Lilius, J.M. (2004), "Compassion in organizational life", American Behavioral Scientist, Vol. 47 No. 6, pp. 808-827, doi: 10.1177/ 0002764203260211.

Kumar, S. and Johnson, M. (2017), "Mentoring doctoral students online: mentor strategies and challenges", Mentoring and Tutoring: Partnership in Learning, Vol. 25 No. 2, pp. 202-222, doi: 10.1080/13611267.2017.1326693.

Kutsyuruba, B. and Godden, L. (2019), "The role of mentoring and coaching as a means of supporting the well-being of educators and students", International Journal of Mentoring and Coaching in Education, Vol. 8 No. 4, pp. 229-234, doi: 10.1108/IJMCE-12-2019-081.

LaBoskey, V.K. (2004), "The methodology of self-study and its theoretical underpinnings", in Loughran, J.J., Hamilton, M.L., LaBoskey, V.K. and Russell, T.L. (Eds), International Handbook of Self-Study of Teaching and Teacher Education Practices, Springer, Dordrecht, pp. 817-869.

Lucey, T.A. and White, E.S. (2017), "Mentorship in higher education: compassionate approaches supporting culturally responsive pedagogy", Multicultural Education, Vol. 24 No. 2, pp. 11-17.

Mullen, C.A. (2012), "Mentoring: an overview", in Fletcher, S.J. and Mullen, C.A. (Eds), The SAGE Handbook of Mentoring and Coaching in Education, Sage, London, pp. 7-23, doi: 10.4135/ 9781446247549.n2.

Mullen, C.A. (2020), "Online doctoral mentoring in a pandemic: help or hindrance to academic progress on dissertations?", International Journal of Mentoring and Coaching in Education, pp. 1-19, doi: 10.1108/IJMCE-06-2020-0029.

Nora, A. and Crisp, G. (2007), "Mentoring students: conceptualizing and validating the multidimensions of a support system”, Journal of College Student Retention, Vol. 9 No. 3, pp. 337-356.

Pepper, M.J., London, T.D., Dishman, M.L. and Lewis, J.L. (2010), Leading Schools during Crisis: What School Administrators Must Know, Rowman and Littlefield Education, Lanham, MD.

Ravitch, S.M. and Carl, N.M. (2016), Qualitative Research: Bridging the Conceptual, Theoretical, and Methodological, Sage, Los Angeles, CA.

Ray, J., Pijanowski, J. and Lasater, K. (2020), “The self-care practices of school principals”, Journal of Educational Administration, Vol. 58 No. 4, pp. 435-451, doi: 10.1108/JEA-04-2019-0073.

Redefining mentorship 
IJMCE

10,2

Sabagh, Z., Hall, N.C. and Saroyan, A. (2018), "Antecedents, correlates and consequences of faculty burnout”, Educational Research, Vol. 60 No. 2, pp. 131-156, doi: 10.1080/00131881.2018.1461573.

Samaras, A.P., Frank, T.J., Williams, M.A., Christopher, E. and Rodick, W.H. (2016), "A collective selfstudy to improve program coherence of clinical experiences", Studying Teacher Education, Vol. 12 No. 2, pp. 170-187, doi: 10.1080/17425964.2016.1192033.

Spillane, J.P. and Lee, L.C. (2014), "Novice school principals' sense of ultimate responsibility: problems of practice in transitioning to the principal's office", Educational Administration Quarterly, Vol. 50 No. 3, pp. 431-465, doi: 10.1177/0013161X13505290.

Stone-Johnson, C. and Weiner, J.M. (2020), "Principal professionalism in the time of COVID-19", Journal of Professional Capital and Community, Vol. 5 Nos 3/4, pp. 367-374, doi: 10.1108/JPCC-052020-0020.

Tedeschi, R.G. and Calhoun, L.G. (2004), "Posttraumatic growth: conceptual foundations and empirical evidence”, Psychological Inquiry, Vol. 15 No. 1, pp. 1-18.

Tidwell, D. and Staples, A. (2017), "The collaborative process in educators' self-study of practice", Dalmau, M.C., Guðjónsdóttir, H. and Tidwell, D. (Ed.s.), Taking a Fresh Look at Education, Sense Publishers, Rotterdam, pp. 89-111.

Trzeciak, S. and Mazzarelli, A. (2019), Compassionomics: The Revolutionary Scientific Evidence that Caring Makes a Difference, Studer Group, Pensacola, FL.

Vanassche, E. and Kelchtermans, G. (2015), "The state of the art in self-study of teacher education practices: a systematic literature review", Journal of Curriculum Studies, Vol. 47 No. 4, pp. 508-528, doi: 10.1080/00220272.2014.995712.

Varney, J. (2009), "Humanistic mentoring: nurturing the person within”, Kappa Delta Pi Record, Vol. 45 No. 3, pp. 127-131.

Woloshyn, V., Savage, M.J., Ratkovic, S., Hands, C. and Martinovic, D. (2019), "Exploring professors' experiences supporting graduate student well-being in Ontario faculties of education”, International Journal of Mentoring and Coaching in Education, Vol. 8 No. 4, pp. 397-411, doi: 10.1108/IJMCE-02-2019-0028.

\section{Corresponding author}

Kara Lasater can be contacted at: klasater@uark.edu

For instructions on how to order reprints of this article, please visit our website:

www.emeraldgrouppublishing.com/licensing/reprints.htm

Or contact us for further details: permissions@emeraldinsight.com 